\title{
25 ANOS DA COLETA SELETIVA DE PORTO ALEGRE: HISTÓRIA E PERSPECTIVAS
}

25 YEARS OF SELECTIVE COLLECTION IN PORTO ALEGRE: HISTORY AND PERSPECTIVES

Caroline Silva da Silva ${ }^{1}$, Luís Felipe Machado do Nascimento ${ }^{2}$

Recebido em: 09 de fevereiro de 2017 Aprovado em: 05 de maio de 2017

\begin{abstract}
RESUMO
A Coleta Seletiva (CS) consiste em uma forma de valorizar os resíduos sólidos recicláveis, uma vez que estes passam a ser selecionados na fonte geradora, não sendo contaminados com o restante dos resíduos sólidos urbanos domiciliares. Em Porto Alegre, a Coleta Seletiva foi implantada em 1990, tendo sido uma das pioneiras no Brasil, apresentando uma abordagem diferenciada do que se fazia na época. $\mathrm{O}$ Departamento Municipal de Limpeza Urbana (DMLU) utilizou um sistema que abrangia desde a geração dos resíduos até a sua destinação final. A pesquisa teve por objetivo não só identificar as principais dificuldades, bem como os avanços obtidos com a CS neste estado ao longo de seus 25 anos. O método empregado foi a realização de um estudo de caso que contou com depoimentos de cinco gestores do DMLU. Os resultados mostram que essa CS foi bem-sucedida, pois sensibilizou a população quanto à importância da correta separação dos resíduos e, em 2015, a CS já abarcava praticamente a totalidade dos bairros da cidade. Segundo estudos do Banco Nacional de Desenvolvimento Econômico e Social (BNDES), em 2013, a CS de Porto Alegre era uma das três melhores do país. Por outro lado, os gestores entrevistados destacam que os resultados poderiam ser bem mais expressivos e atingir um maior percentual de resíduos coletados, além de uma triagem mais eficiente. Como perspectiva, os entrevistados indicam que a gestão integrada de resíduos deveria voltar-se para a diminuição da produção de resíduos e caberia às empresas assumirem maior responsabilidade com a logística reversa dos produtos que comercializam.
\end{abstract}

Palavras-chave: Coleta Seletiva. Resíduos Sólidos. Porto Alegre. Reciclagem. Catador.

\section{ABSTRACT}

Selective collection systems are intended to obtain the maximum value from recyclable solid waste, by separating it at source from non-recyclable waste. In Brazil, the city of Porto Alegre was a pioneer in introducing its Selective Collection System in 1990 and adopted a different approach from other cities at the time. The Municipal Department of Waste Collection (DMLU) introduced a system that encompassed the full trajectory of waste from its source to its final destination. The objective of this research was to identify the main difficulties and advances obtained with the introduction of the Selective Collection System in Porto Alegre over its 25 years. To achieve that a case study was conducted that included interviews with five managers of the DMLU. The results show that the Selective Collection System in Porto Alegre has been successful in raising the awareness of the population regarding the importance of separating different types of waste and, by 2015 , Selective Collection System covered practically $100 \%$ of the city's districts. According to a study conducted by the National Economic Development Bank (BNDE) in 2013, the Selective Collection System in Porto Alegre was one of the three best in Brazil. On the other hand, the managers interviewed emphasize that the results could be much better, collect a higher percentage of waste and sort it more efficiently. The respondents suggest that, in the future, integrated waste management should focus on reducing waste production and encouraging companies to take greater responsibility for the reverse logistics of the products they market.

Keywords: Selective Collection. Solid Waste. Porto Alegre. Recycling. Waste Collector.

\footnotetext{
Bacharel em Administração (Universidade Federal do Rio Grande do Sul/Brasil). E-mail: scarols@ gmail.com.

${ }^{2}$ Doutor em Economia e Meio Ambiente (Universität Gesamthochschule Kassel/Alemanha). Professor na Universidade Federal do Rio Grande do Sul (Porto Alegre/Brasil). E-mail: nascimentolf@gmail.com.
} 


\section{INTRODUÇÃO}

O aumento na produção de resíduos representa um problema mundial tendo em vista que as motivações para esse cenário são diversas e agravam-no. A solução definitiva e sustentável parece não existir, pois a alocação dos resíduos descartados desafia governos do mundo inteiro. $\mathrm{O}$ aparecimento de territórios considerados de alto risco para a população, como lixões, encontra-se diretamente associado a esse problema. Em face disso, a corrida para minimizar o impacto do descarte nas cidades vai desde a "terceirização" do seu depósito até a criação de aterros sanitários e a segmentação da coleta domiciliar. Convém ressaltar que, segundo a Organização Internacional do Trabalho, 80\% do lixo eletrônico dos países ricos são enviados a países em desenvolvimento, sendo que "boa parte [...] é enviado ilegalmente" (BBC, 2013).

O Departamento Municipal de Limpeza Urbana (DMLU) estima que, entre 2001 e 2011, a geração média de resíduos sólidos domiciliares regulares em Porto Alegre aumentou de 912 para 1.020,5 t/dia útil, um crescimento de 12\%, contra um aumento populacional de 3\% (PMGIRS; p. 53 e 54). Uma vez que a quantidade e a variedade de resíduos só têm aumentado e parece não existir nenhum esforço para a redução do consumo, a reciclagem é apresentada como uma das soluções mais utilizadas para diminuir o impacto dos resíduos sólidos. A Coleta Seletiva compreende uma operação que viabiliza a maior efetividade de reciclagem, visto que incentiva a separação prévia do material diretamente na fonte geradora, evita que esse resíduo passível de ser reciclado seja contaminado pela matéria orgânica, possibilitando, portanto, o maior aproveitamento dos materiais e a diminuição dos custos de reciclagem.

A Coleta Seletiva, além dos aspectos ambiental e econômico da cadeia de reciclagem, possui uma relevante função social, gerando postos de trabalho e renda a pessoas dos setores mais desfavorecidos da sociedade. De acordo com o IPEA (2011 apud 2013), a partir de dados extraídos da Pesquisa Nacional de Saneamento Básico realizada pelo IBGE em 2008, foram identificados 1.175 associações de catadores, contando com cerca de 30.400 trabalhadores. Em Porto Alegre, o Sistema de Coleta Seletiva começou a operar no dia 7 de julho de 1990. O sistema implantado foi considerado vanguardista no Brasil, tendo sido iniciada com um projeto piloto num bairro e, em apenas seis anos, conseguiu estender o programa para atender toda a cidade. Isto só foi possível graças a uma forte ação de educação ambiental e ao investimento na capacitação dos coletores, que acarretou a adesão de grande parte da população.

Em 2015, a sistema de Coleta Seletiva completou 25 anos de operação em Porto Alegre, tempo suficiente para a consolidação da experiência. Portanto, ao iniciar esta pesquisa a expectativa era de que, ao longo do referido período, a Coleta Seletiva tenha sido aprimorada e a população tenha incorporado a cultura da separação de resíduos sólidos urbanos domiciliares. Partindo dessas suposições, esse trabalho teve por objetivo não só identificar as principais dificuldades e os maiores avanços obtidos com a implantação da Coleta Seletiva em Porto Alegre, bem como as perspectivas de desenvolvimento.

\section{REVISÃO TEÓRICA}

Com o intuito de embasar esse trabalho, considera-se válido não somente conceituar os resíduos sólidos, a reciclagem e a coleta seletiva, assim como verificar a bibliografia relacionada à situação da coleta seletiva no Brasil como um todo. 


\subsection{RESÍDUOS SÓLIDOS}

De acordo com Calderoni (2003), as definições de rejeito, lixo e resíduo são diferentes quando aplicadas em contextos diversos. O resíduo refere-se a tudo aquilo que sobra de um processo produtivo; o rejeito corresponde ao material que, após um processo de seleção, não é aproveitado; enquanto o lixo é o material sólido que não passa por nenhuma seleção e é descartado pelo proprietário. Os resíduos pertinentes a essa pesquisa são os sólidos domiciliares, os quais o DMLU (2015), separa em dois grupos, conforme designados a seguir:

a) os domiciliares são compostos por resíduos orgânicos (resíduo de origem animal ou vegetal) e rejeitos (materiais que não podem ser aproveitados, como lacres de laticínios, papel higiênico, absorventes e fraldas descartáveis);

b) os recicláveis são aqueles materiais que podem ser reciclados, compostos, principalmente, de embalagens de plástico, vidro, papel seco e metal.

Essa separação de conceitos pretende, sobretudo, ajudar ao cidadão a identificar os resíduos a serem dispostos para a coleta tradicional, responsável por recolher os resíduos orgânicos e rejeitos. A coleta seletiva recolhe o material reciclável, que engloba os resíduos domiciliares "domésticos", provenientes de residências, e o "comercial", advindos deste tipo de estabelecimento.

\subsection{RECICLAGEM E COLETA SELETIVA}

A reciclagem compreende um processo que visa recuperar e reutilizar resíduos a fim de devolvêlos à sociedade como uma matéria útil para um novo processo produtivo. Portanto, transforma os resíduos descartados em materiais que são denominados de secundários e servem para substituir as matérias-primas na produção de um novo produto. Conforme Ribeiro e Lima (2000), a necessidade de reciclar foi percebida a partir da observação da carência de recursos naturais aliada à problemática de disposição final dos resíduos no meio ambiente. Ainda de acordo com estes autores, as situações de crise e de extremo racionamento, como no caso de guerras, desenvolveram a mentalidade de repúdio ao desperdício e o reaproveitamento de matéria-prima para reciclagem. Sachs (2000) salienta que a civilizações sobreviveram em virtude dos recursos da natureza, portanto, seria irracional esgotá-los. Neste sentido, a Coleta Seletiva configura-se como um meio de recuperar recursos e economizar recursos naturais.

O principal motivador da reciclagem, na visão de Ribeiro e Lima (2000), reside no fator econômico, ou seja, para um material qualquer não se tornar rejeito é preciso que haja mercado para ele. Para que exista interesse nestes produtos, é necessária a existência de certo volume, pois materiais em pequenas quantidades não despertam interesse para reciclagem, bem como dependem de apresentar um valor atrativo no mercado.

Segundo Calderoni (2003), a reciclagem significa também uma maneira de educar e conectar as pessoas ao meio ambiente, visto que desenvolve a sensação de pertencimento e, por intermédio de pequenas ações, permite reduzir os impactos a sua volta. Essa sensação de pertencer é imprescindível para o êxito de um processo de reciclagem, que tem a Coleta Seletiva como uma das suas principais etapas e depende muito da adesão da população. Por meio da coleta seletiva, é possível recolher materiais reutilizáveis já devidamente separados direto na fonte geradora (BRINGHENTI, 2004).

Os Estados Unidos, a Europa e o Japão foram os pioneiros em reciclagem com participação do poder público, cujas iniciativas receberam o apoio de empresas e outras organizações, além do forte engajamento da população como um todo. Para Prado, Philippi Jr. e Santana (2015), a iniciativa do 
poder público com a Coleta Seletiva visa, entre outras vantagens, aumentar a vida útil e reduzir as emissões atmosféricas dos aterros, que, como sabido, contribuem para o aquecimento global. De acordo com a Comissão Empresarial para a Reciclagem - Cempre (2014), a implantação de um Sistema de Coleta Seletiva passa pelas fases descritas no Quadro 1.

Quadro 1 - Fases de implantação de um Sistema de Coleta Seletiva

\begin{tabular}{|c|l|}
\hline Fase & \multicolumn{1}{c|}{ Descrição } \\
\hline Diagnóstico & $\begin{array}{l}\text { Consiste no estudo de diferentes fatores envolvendo a população e o ambiente no qual se quer inserir o } \\
\text { sistema }\end{array}$ \\
\hline Planejamento & Nessa fase ocorre a escolha do modelo da coleta seletiva e a análise de fatores operacionais \\
\hline Implantação & $\begin{array}{l}\text { Verifica-se a periodicidade, a distribuição dos dias da semana e a quantidade de viagens necessárias à } \\
\text { coleta }\end{array}$ \\
\hline $\begin{array}{c}\text { Operação e } \\
\text { monitoramento }\end{array}$ & Com o sistema em operação, acompanham-se os indicadores de desempenho \\
\hline $\begin{array}{c}\text { Análise dos } \\
\text { benefícios }\end{array}$ & Consiste em contabilizar os ganhos ambientais, econômicos e sociais advindos do sistema implantado \\
\hline
\end{tabular}

\section{Fonte: Cempre (2014)}

Para o sucesso e a continuidade de um programa de coleta seletiva é fundamental o desenvolvimento correto dessas fases. Além disso, todas as variantes devem ser observadas, do início ao fim.

\subsection{COLETA SELETIVA NO BRASIL}

Por meio da pesquisa Ciclosoft do Cempre (2014), pode-se verificar uma evolução nos programas de coleta seletiva no Brasil, consequência de diversas políticas públicas como, por exemplo, as criações da Secretaria Nacional de Saneamento Ambiental na estrutura do Ministério das Cidades, do Comitê Interministerial Lixo e Cidadania e da aprovação da Política Nacional de Resíduos Sólidos. Chama a atenção o crescimento do número de municípios brasileiros com um sistema de coleta seletiva implantado. Em 2008, a pesquisa contabilizou 405 cidades com sistemas de coleta seletiva e em 2014 esse número passou para 927, isto significou um crescimento de $128 \%$ em apenas seis anos de existência.

Apesar de ter ocorrido um crescimento bastante expressivo em relação ao número de municípios que implantou a coleta seletiva, quando se analisa o número de pessoas atendidas, os resultados estão longe de ser tão positivos. No período de seis anos, o número de cidadãos brasileiros atendidos pelo sistema de coleta seletiva cresceu somente 7,69\%, passando de 26 milhões para 28 milhões de pessoas. Portanto, nos últimos anos houve um crescimento de iniciativas visando à coleta seletiva nos municípios, contudo, a situação da destinação adequada dos resíduos sólidos urbanos é ainda preocupante na maioria dos municípios brasileiros. Segundo Bringhenti (2004), a situação precária dos serviços de limpeza urbano no Brasil deve-se, principalmente, a questões como "descontinuidade política e administrativas, limitações financeiras e orçamentos inadequados, tarifas/taxas desatualizadas, arrecadações insuficientes e recursos humanos com baixa capacitação técnica" (BRINGHENTI, 2004, p. 25). Assis, Malheiros, Fernandes e Philippi Jr. (2012) realizaram uma avaliação das políticas ambientais públicas e destacaram a dificuldade de obtenção de dados para avaliar os impactos destas políticas em longo prazo. 


\section{METODOLOGIA}

Para atingir os objetivos propostos, optou-se por realizar um estudo de caso, pois conforme Yin (2010), se uma pesquisa procura explicar algum fenômeno ou circunstância presente, é adequado utilizar a metodologia de estudo de caso. Para Roesch e Fernandes (2007), na produção de um estudo de caso deve-se considerar a diferença entre a reprodução fiel do objeto, tal qual é percebido por todos, da descrição subjetiva, retratada segundo a interpretação do relator. Embora o caso da Coleta Seletiva envolva diferentes agentes, o foco desse estudo foi a percepção dos representantes do poder público, ou seja, os idealizadores e os gestores operacionais da Coleta Seletiva ao longo dos seus 25 anos. Tais agentes foram questionados acerca dos objetivos iniciais do Projeto, das barreiras e dos resultados obtidos nesse período. As conclusões das entrevistas são descritas em formato de narrativa, nas quais os fatos se sucedem de maneira cronológica, o último, simbolicamente, representado como o ano de 2015 (SANCHEZ apud ROESCH; FERNANDES, 2007).

Para delimitação da amostra adaptou-se o método Bola de Neve, que pressupõe existir uma ligação entre os membros de uma mesma população, que são capazes de se identificar e indicar outro membro para compor a amostragem (FAUGIER; SARGEANT, 1997). No caso em questão, a escolha da amostragem de entrevistados teria sido difícil caso não houvesse alguém do DMLU para indicar os personagens chaves. Os resultados apresentados foram obtidos por meio de entrevistas realizadas com cinco gestores, dentre os quais, três exerceram o cargo de diretor-geral do DMLU, ao passo que os outros dois ocuparam vários cargos relevantes no referido órgão durante o período analisado. As entrevistas foram feitas em 2015, tendo seguido um roteiro com questões abertas a fim de incentivar respostas longas e detalhadas.

\section{ANÁLISE DOS RESULTADOS}

Com mencionado anteriormente, foram realizadas entrevistas com cinco gestores que participaram do processo de implantação da coleta seletiva durante um período de 25 anos. No Quadro 2 são listados os cargos por eles assumidos, como serão referenciados neste trabalho e informações complementares sobre a sua trajetória no DMLU.

Quadro 2 - Gestores do DMLU entrevistados nesta pesquisa

\begin{tabular}{|c|c|c|}
\hline Referenciado como & Cargo & Complemento \\
\hline Diretor-Geral 1 & $\begin{array}{l}\text { Diretor-Geral do } \\
\text { DMLU }\end{array}$ & Responsável pela implantação da coleta seletiva, foi diretor por mais de dez anos \\
\hline Diretor-Geral 2 & $\begin{array}{l}\text { Diretor-Geral do } \\
\text { DMLU }\end{array}$ & $\begin{array}{l}\text { Agrônomo integrante da Equipe de Assessoria Técnica de Planejamento e } \\
\text { Desenvolvimento (Assteplad) }\end{array}$ \\
\hline $\begin{array}{l}\text { Diretor-Geral } \\
\text { Substituto }\end{array}$ & $\begin{array}{l}\text { Diretor-Geral do } \\
\text { DMLU }\end{array}$ & $\begin{array}{l}\text { Foi gerente operacional da Coleta Seletiva nos anos } 1991 \text { e 1992; supervisor } \\
\text { administrativo e financeiro; diretor-geral substituto do DMLU; e, em 2015, fazia } \\
\text { parte da equipe da Assteplad. }\end{array}$ \\
\hline $\begin{array}{l}\text { Diretor da Divisão } \\
\text { de Limpeza e Coleta } \\
\text { (DLC) }\end{array}$ & Diretor da DLC & Em 2015 era o diretor da DLC \\
\hline $\begin{array}{l}\text { Coordenador } \\
\text { Assteplad }\end{array}$ & $\begin{array}{l}\text { Coordenador } \\
\text { Assteplad }\end{array}$ & $\begin{array}{l}\text { Em } 2015 \text { era o coordenador da Assteplad. Profissional que atua há } 24 \text { anos no } \\
\text { DMLU }\end{array}$ \\
\hline
\end{tabular}

Fonte: Os autores 


\subsection{O INÍCIO DA COLETA SELETIVA: PLANEJAMENTO E IMPLANTAÇÃO}

Porto Alegre teve uma longa história de descaso em relação aos resíduos sólidos urbanos, desde a desvalorização do profissional que trabalhava na área até a maneira irresponsável do destino dado a estes resíduos. De acordo com o diretor-geral 2, a administração pública não dava a devida atenção ao serviço, resultando em um impacto não só ambiental como também social, pois além da poluição do solo e da água, havia uma grande população que vivia, literalmente, em cima do lixo. Essa relação irresponsável com o lixo prevaleceu por muitos anos e, em razão disto e da falta de qualificação técnica do DMLU, este era considerado irrelevante.

Com a ascensão do Partido dos Trabalhadores (PT) à frente da Prefeitura, em 1989, a questão social do lixo passou a ser evidenciada e uma nova visão de gestão de resíduos foi se criando. Segundo o diretor-geral 2, a crise instaurada nos lixões forçou um movimento interno da administração de conscientização sobre a importância do tratamento e a correta destinação dos resíduos. A partir disso, passou a se discutir soluções para amenizar o seu impacto. As gestões do PT na Prefeitura de Porto Alegre se estenderam de 1989 a 2004. Ao assumir o cargo, em 1989, o prefeito Olívio Dutra encontrou os dois principais lixões de Porto Alegre com a capacidade praticamente esgotada e a população neles inserida vivendo em condições subumanas. Juntamente com a prefeitura, o DMLU, que estava sob nova direção, buscaram ações para reverter a situação crítica com que se deparava o Departamento.

Ainda em 1989, identificou-se que a Coleta Seletiva era uma opção possível, apesar dos escassos recursos financeiros e da pouca capacidade técnica disponível na época. Foram contratados engenheiros e sociólogos como assessores técnicos para participarem do projeto. A inspiração da Coleta Seletiva de Porto Alegre surgiu num seminário promovido pelo Instituto Goethe e pela AEBA, com participação ativa do DMLU, onde se discutiu a relação da coleta seletiva e a reciclagem dos resíduos com a recuperação de marginalizados. A partir deste seminário, o DMLU definiu o formato do projeto de Coleta Seletiva a ser implantado em Porto Alegre. A primeira ação tomada pela prefeitura, naquele ano, foi iniciar o projeto de recuperação da área degradada dos lixões das Zonas Sul e Norte. No lixão da Zona Norte, houve um extenso trabalho de conscientização e reabilitação dos catadores que lá trabalhavam. Foram estabelecidas regras e obrigações que incluíam a proibição de instalar moradia no lixão; a permanência só era permitida em horário de expediente, além de se proibir o trabalho infantil nos lixões.

A Coleta Seletiva permitiu que os trabalhadores fossem tirados de cima do lixo e realocados em lugares adequados, dentro da área do lixão, mas afastados do local onde aconteciam os desembarques dos caminhões da coleta tradicional. Neste novo espaço, os trabalhadores faziam a triagem do material vindo exclusivamente da Coleta Seletiva, a qual, por sua vez, propiciou a inclusão dos chamados "catadores dos lixões", oferecendo melhores condições de trabalho e melhor remuneração. A partir de então, em vez de recolher material com valor comercial do lixão, os trabalhadores passaram a fazer a triagem do "lixo seco" recebido, isto é, resíduos já separados pela população e entregues para a Coleta Seletiva.

Para o diretor-geral 2, a principal mudança implementada pela Administração Popular foi a transformação na forma de encarar e tratar a questão do lixo.

O momento foi inovador para cidade porque se saiu de uma situação na qual coletas em vila eram esporádicas, gerando depósitos irregulares e foco de lixo em vilas, dois lixões a céu aberto em área de banhado para uma situação em que a Prefeitura propõe: 'vamos fazer concurso para gari; vamos investir na limpeza urbana da cidade e fazer uma gestão integrada. A separação do lixo será feito na origem, com o apoio da população’ (Diretor-Geral 2). 
Paralelamente à recuperação dos lixões, o DMLU contratou uma equipe de profissionais para planejar e encontrar meios de colocar em prática o projeto de Coleta Seletiva. Foi iniciada uma campanha de educação ambiental a fim de conscientizar a população a respeito da importância da separação dos resíduos sólidos domiciliares e o seu impacto quando mal disposto. A Coleta Seletiva teve início no Bairro Bom Fim, escolhido por ser considerado o epicentro cultural, devido à concentração de artistas e intelectuais que residiam e circulavam neste bairro. Estas pessoas eram mais abertas às inovações e eram formadores de opinião.

No sábado, dia 7 de julho de 1990, foi iniciada oficialmente a Coleta Seletiva. O diretor-geral 1 relata que uma estrutura com palco foi montada no Parque da Redenção, com a apresentação de artistas locais. De lá partiu o primeiro caminhão. Os artistas, juntamente com profissionais do DMLU, percorreram o bairro para divulgar e chamar a atenção da população para o que estava acontecendo. $\mathrm{O}$ diretor-geral 1 informa terem sido comprados dois caminhões para iniciar a Coleta Seletiva no bairro Bom Fim. Os caminhões eram caracterizados e se diferenciavam dos caminhões da coleta tradicional. Cada caminhão percorria as ruas do bairro tocando uma sineta enquanto os funcionários batiam de porta em porta para recolher o lixo reciclável. Os moradores entregavam o "lixo seco" em mãos. Essa abordagem bastante próxima do cidadão foi possível com os esforços de capacitação dos garis para terem uma correta atitude para com os moradores, no intuito de orientar e aumentar a adesão ao programa.

O diretor-geral 1 lembra que, logo que foi implantada a Coleta Seletiva no Bom Fim, a Associação de Moradores do Bairro Cidade Baixa solicitou que o projeto fosse levado também para a Cidade Baixa. Cerca de dois a três meses depois, a Coleta Seletiva já estava operando na Cidade Baixa. Foi realizado o mesmo processo de preparação dos moradores, com divulgação e um trabalho de educação ambiental e, no dia da implantação, foi organizado um evento semelhante ao da inauguração do serviço no Bom Fim.

A Coleta Seletiva permaneceu restrita a esses dois bairros até o DMLU conseguir recursos para expandir o serviço. O material recolhido era direcionado para a Associação de Catadores do Lixão da Zona Norte, que já estavam organizados para fazer a triagem desse material. A Unidade de Triagem ficou conhecida como "galpão de reciclagem", embora não fizesse reciclagem, visto que o trabalho realizado era apenas de separação do vidro, plástico, papel, metais etc. Uma vez separado, o material era comercializado pela "Associação dos Catatores", pois os trabalhadores nos galpões continuavam sendo chamados de "catadores". Posteriormente, passaram a ser chamados de "recicladores" e a associação de "Associação/Cooperativa de Recicladores".

Segundo a maioria dos entrevistados, o ano de 1990 foi um divisor de águas para o DMLU. Os problemas relacionados com o recolhimento e a destinação dos resíduos da cidade eram profundos e urgentes. Com a nova administração, iniciada em 1989, cresceu a credibilidade do DMLU e, no final 1990, o departamento conseguiu dar fim a maioria dos lixões irregulares, bem como a recuperação do Lixão da Zona Norte. A população percebeu que a cidade estava mais limpa.

\subsection{A CONSOLIDAÇÃO E EXPANSÃO DO SERVIÇO}

Em 1989, a maioria dos funcionários do DMLU era celetista. O Diretor Substituto recorda-se dos esforços envidados para reestruturar o Departamento com de concursos públicos. Entretanto, o diretorgeral 1 esclarece que grande parte dos garis pertencia à Cooperativa Cootravipa. A justificativa era de que, por ser um serviço que exigia resistência física e onde ocorria muita rotatividade, tornava-se insustentável o modelo estatutário, já os motoristas dos caminhões eram concursados do Departamento. 
A demanda de mão-de-obra gerada pelo serviço da Coleta Seletiva foi uma das justificativas para a reestruturação do Departamento. Conforme o diretor substituto, a confiança da população em relação à Coleta Seletiva dependia da frequência e assiduidade dos caminhões. A prefeitura estava disposta a expandir a Coleta Seletiva para outros bairros. Embora o DMLU possuísse pessoal, contava com apenas três caminhões para o serviço. Segundo o diretor substituto, o DMLU estava consciente de que, uma vez implantada a Coleta Seletiva em novos bairros, teria de garantir a qualidade do serviço ou perderia a confiança que vinha conquistando.

O DMLU formulou três premissas para a gestão da Coleta Seletiva: a) o serviço seria prestado pelo próprio Departamento; b) haveria investimentos em capacitação permanente dos servidores; e c) o serviço seria ofertado de forma consistente e ininterrupta para toda a cidade. Os recursos originados da taxa de coleta de lixo e da taxa de limpeza urbana, pagas pela população através do IPTU, asseguravam o orçamento do DMLU e lhe proporcionavam certa autonomia para gerenciar estes recursos. Quando eram necessários recursos adicionais, esta demanda era discutida na previsão de orçamento do ano seguinte.

Segundo o diretor substituto, excluindo o investimento inicial para implantar a Coleta Seletiva, os recursos necessários para sua manutenção consistiam basicamente de combustível para os caminhões, manutenção dos veículos e do quadro de funcionários. A dificuldade encontrada se relacionava com a expansão do serviço, que demandava decisões concernentes não somente ao Departamento, como também à própria prefeitura. Ainda de acordo com o referido diretor, no segundo semestre de 1991, o DMLU adquiriu dez novos caminhões para a Coleta Seletiva, decisão baseada na autonomia orçamentária do Departamento e não foi precisou da aprovação da prefeitura. No depoimento do diretorgeral 1, esse "desvio" orçamentário foi compensado com a organização e cobrança do serviço de Coletas Especiais (resíduo hospitalar, contratos com condomínios etc.).

Com a compra desses veículos, começou o trabalho de implantar a Coleta Seletiva naqueles bairros que queriam ou necessitavam do serviço. A Coleta Seletiva acontecia em dias ou turnos propositalmente diferentes dos da coleta convencional em cada bairro. Essa decisão contribuiu para a visibilidade da Coleta Seletiva, pois acontecia no período diurno, o que ajudava ainda mais os moradores a identificar o serviço que estava sendo prestado. A partir do crescimento da Coleta Seletiva, a quantidade de resíduos coletados passou a exceder a capacidade dos galpões de reciclagem existentes. Diante desta nova demanda, o DMLU construiu, com recursos próprios, novos galpões e entregou para associações de recicladores que faziam a triagem do lixo seco e, posteriormente, comercializavam o papel, vidro, plástico e metais que haviam sido separados. Conquanto estes galpões fossem patrimônio do poder público, a administração e a manutenção dos galpões eram feitas pelos trabalhadores das associações.

O diretor-geral 1 explicou que, de 1991 a 1996, além da associação já existente na Ilha dos Marinheiros, foram criadas as associações do Aterro da Zona Norte, da Vila Dique, do Campo da Tuca, da Wenceslau Fontoura, da Vila Cai-Cai, da Vila Bom Jesus. Essa informação corrobora com a de Pereira (1997), ao dispor que, no mesmo período, foram criadas oito Associações, a maioria com o galpão construído pela prefeitura. Em 2015, segundo informação oficial do DMLU, em Porto Alegre existiam dezenove Unidades de Triagem conveniadas.

O diretor substituto afirma que, em 2015, a relação entre as Associações de Recicladores e o DMLU encontra-se mais formalizada, com mecanismos de controle e fiscalização por parte do Departamento, bem como existem termos de cooperação e determinação das responsabilidades, deveres e obrigações das duas partes. Uma dessas obrigações é o repasse financeiro, por parte do Departamento aos galpões. 
As associações recebem valores que variam de $\mathrm{R} \$ 2.500,00$ a $\mathrm{R} \$ 4.000,00$ por mês para custear a manutenção e o funcionamento do galpão. Se alguma associação não recebe é porque ela não assinou o termo de cooperação ou porque o termo venceu e não foi feito o aditivo, ou ainda, porque a associação não fez a prestação de contas (Diretor Substituto).

Enquanto o diretor-geral 1 entende que, por não existir mais uma Federação das Associações de Catadores, que tinha uma participação bastante ativa e unificava as associações em prol de um mesmo objetivo, hoje o movimento dos catadores é bem menos articulado e atuante. Houve um enfraquecimento do poder de pressão das associações junto à prefeitura. Quanto à venda do produto final dos galpões, o diretor substituto esclarece que o Departamento se limita a indicar empresas que compram as matériasprimas papel, vidro, plásticos, metais etc. ofertados pelas unidades de triagem. Quando necessário, o Departamento acompanha as negociações entre as partes, mas não intermedia nem faz a venda do material. Como uma forma de auxiliar nas negociações entre os galpões e as empresas, o DMLU informava os valores médios dos materiais negociados no mercado da reciclagem para que nenhuma das partes se sentisse lesada.

À medida que o serviço de Coleta Seletiva foi se espalhando para mais bairros, um grupo de pessoas ficou responsável pelo gerenciamento operacional do serviço, indicando o itinerário de cada caminhão e o galpão de destino. As premissas utilizadas para indicar quais caminhões iriam para cada galpão, eram basicamente o número de trabalhadores e a sua capacidade produtiva do galpão. Com a incorporação de novos bairros, crescia a quantidade de resíduos coletados. Quando iniciava a Coleta Seletiva num novo bairro, o volume de resíduos coletados era bastante pequeno, porém, a proporção que o serviço era divulgado e a população se familiarizava com este, o volume aumentava até alcançar um ponto de estabilidade. Essa curva de crescimento inicial implicava o replanejamento dos veículos e seus trajetos.

Já na metade da década de 90, a Coleta Seletiva se tornou uma sessão importante dentro do Departamento, tanto que se transferiu para a Avenida Wenceslau Escobar. Nessa época, segundo o diretor substituto, o Departamento já contava com uma frota de mais de 25 veículos rodando somente para a Coleta Seletiva. Embora o diretor-geral 2 informe que a Coleta Seletiva teve uma aceitação muito grande por parte da população e, em 1996, já abrangia todos os bairros da cidade, o diretor-geral 1 afirma que esse número só foi alcançado entre 2000 e 2002. A zona rural do Município de Porto Alegre era a que mais onerava, dado as distâncias entre as residências e o baixo volume coletado.

Quanto à influência política dos partidos ou governantes de Porto Alegre, o diretor substituto pontua que a troca de governos não causou prejuízos para a Coleta Seletiva. Ao contrário, segundo ele, a cada novo governo, novas pessoas eram trazidas para o departamento, diversificando a discussão, resultando em melhorias para o sistema. Uma dessas ideias foi a de transformar cada unidade do DMLU em Postos de Entrega Voluntárias, ou seja, o cidadão poderia levar seus resíduos diretamente nas unidades do DMLU espalhadas pelos bairros da cidade. Outra ação acontecida recentemente consistiu na ampliação do serviço de Coleta Seletiva, que passou de um para dois dias por semana.

Ainda segundo o diretor substituto, em 2015, não havia nenhuma intenção de prejudicar a Coleta Seletiva, uma vez que havia se tornado um serviço de tamanho relevo que deixou de ser considerado como um projeto de governo para se tornar um projeto de gestão pública. Reduzir a importância ou eliminar um serviço que possui uma boa reputação junto à população e tem grande importância socioambiental causaria um grande desgaste político para os governantes. Entretanto, um contraponto é levantado pelo diretor-geral 2, que credita o sucesso do projeto da Coleta Seletiva ao fato deste ter sido 
concebido como uma política social. No seu entendimento, para ter chegado a $100 \%$ das ruas da cidade e ter chegado aonde chegou, foi fundamental a continuidade desta política e qualificação das pessoas envolvidas ao longo dos dezesseis anos de governo do PT na Prefeitura de Porto Alegre.

Sobre a terceirização total do serviço, o diretor substituto afirma que ela aconteceu pela dificuldade do poder público de lidar com o desgaste dos veículos. Para mantê-los operando ou renovar a frota é preciso passar por um longo processo de licitação, que não combina com o imediatismo demandado por esse serviço. A administração pública se viu obrigada a formalizar e lançar uma licitação para contratar uma empresa especializada, a fim de garantir, tanto para a população quanto para as Unidades de Triagem, a frequência da Coleta Seletiva. Trata-se de um assunto polêmico dentro da administração pública, nem todos os entrevistados compartilham da mesma opinião. Para alguns, com a terceirização não se pode garantir a qualidade do serviço prestado. Há quem diga que, depois da terceirização, certas ruas, que antes eram atendidas, agora não são mais atendidas pela Coleta Seletiva.

O diretor substituto esclarece que o departamento tenta garantir que o serviço seja prestado sem prejuízo, porém não cabe ao DMLU obrigar à empresa acessar vielas intransitáveis ou fazer com que se perca tanto tempo fazendo o recolhimento a pé. Perguntado se, nesses casos, existe a orientação aos moradores de disponibilizar seus resíduos em um determinado local, ele afirma não saber informar, mas acha pouco provável, pois sempre se teve o cuidado de que os moradores disponibilizassem seus resíduos em frente de suas casas e não induzi-los a acumularem resíduos diante da casa de algum vizinho.

\subsection{A COLETA SELETIVA EM 2015: EVOLUÇÃO OU ESTAGNAÇÃO?}

A forma de interagir com a população era feita por intermédio dos jornais, rádios e televisão. Isto permitia informar a população e sensibilizá-la para participar da Coleta Seletiva. A cidade foi dividida em zonas para a realização da coleta e entrega do material coletado para o galpão mais próximo. Segundo o coordenador Assteplad, o Departamento de Engenharia de Roteiro de Coleta do DMLU passou a dimensionar as rotas de maneira que cada caminhão faça de duas a três viagens por turno, levando em consideração a quantidade de resíduo por região, e não mais por bairro.

Para o diretor substituto, a divisão entre bairros, que se tornou uma característica do sistema, era também um limitador de eficiência do processo. Se ao terminar o bairro, o caminhão encontrasse-se vazio, não poderia continuar a coleta para o bairro vizinho. Com essa nova forma de dividir a cidade, a mesma rua pode ter dois dias de coletas diferentes, dependendo da rota planejada pelo departamento. Para saber, o cidadão precisa inserir as informações sobre o seu logradouro e o sítio eletrônico do DMLU informará os dias e turnos previstos de coleta para aquele endereço.

Essa nova forma de segmentar o serviço foi um dos fatores que possibilitou à gestão que governava Porto Alegre, em 2015, a aumentar o número de dias de coleta para três dias por semana. Além disto, o novo contrato de licitação estabeleceu o aumento de número de veículos. Em pesquisa no sítio eletrônico do DMLU, percebe-se que, em alguns bairros, isso se tornou realidade.

O diretor da DLC identifica uma melhora com a troca da empresa de coleta. Quando se analisa o material coletado pelo peso dá uma falsa impressão de ser pouco. No entanto, segundo este, como o material da Coleta Seletiva é geralmente leve, esse peso representa um volume bastante grande de material, totalizando a carga de 60 a 70 caminhões/dia. Vale frisar que a empresa anterior atuava com 40 a 50 caminhões. $\mathrm{O}$ entrevistado acredita que esse incremento no recolhimento se deve tanto aos esforços do DMLU em campanhas de conscientização como também ao aumento de roteiros de coleta, passando de 82 para 95 roteiros. 
Conforme explica o coordenador Assteplad, a densidade específica do material reciclado é menor que a do material orgânico. Além disso, os caminhões de coleta tradicional possuem compactadores, que fazem com que o mesmo volume comporte muito mais massa. Isto explica porque a Coleta Seletiva é mais cara do que a tradicional, pois o número de viagens necessário para arrecadar o mesmo peso de material será três a quatro vezes maior.

Em 2013, de acordo com os dados fornecidos pelo DMLU ao SNIS (Sistema Nacional de Informações de Saneamento), o custo unitário da coleta tradicional foi de $\mathrm{R} \$ 89,55$ por tonelada. Em 2015, de acordo com o coordenador Assteplad, o custo era de $\mathrm{R} \$ 115,00$ a tonelada. O cálculo para o custo da coleta tradicional é bastante preciso, pois o pagamento do consórcio se baseia na tonelada coletada. Desta forma, o DMLU tem conhecimento exato da quantidade de resíduos coletados, tendo em vista que todos os caminhões da coleta tradicional passam por uma pesagem. Já o cálculo do custo da Coleta Seletiva revela-se mais complexo devido à falta de uma estatística confiável ou uma base de cálculo homogênea. Como a destinação final é feita diretamente nas dezenove Unidades de Triagem, espalhadas em diferentes pontos da cidade, as quais não são equipadas com balança, não existe um indicador exato de massa coletada.

Em 2015, o DMLU trabalhava com uma estimativa feita através da pesagem do rejeito e da quantidade de material vendido por cada unidade, informação que recebia mensalmente de cada Unidade de Triagem. O rejeito representa, em média, de $25 \%$ a $30 \%$ do material coletado. Todo material recebido por uma galpão é triado, aquilo que não é aproveitado é direcionado para o aterro sanitário e, neste momento, é pesado.

[...] existe uma parcela do rejeito que é resultado da separação incorreta; tem coisas que teoricamente são recicláveis, mas os galpões não conseguem vender porque ou não tem mercado ou não vale a pena. Por outro lado, como o pessoal dos galpões é remunerado pelo tipo de material separado, eles separam aquilo que vale mais. Se o sistema fosse automatizado, a maioria do rejeito poderia ser aproveitado (Coordenador Assteplad).

A quantidade de material coletado corresponde a uma estimativa e, apesar do DMLU acreditar estar bem próximo da realidade, pode haver uma margem de erro. Os galpões recebem o material dos caminhões do DMLU e o material de terceiros (shopping centers, empresas etc.), o que gera uma distorção dos dados relativos à Coleta Seletiva feita pelo Departamento. Como os caminhões da Coleta Seletiva não são pesados, o pagamento não é feito por tonelada e sim pelo tamanho da equipe empregada para fazer a coleta, a estimativa de custo se baseia na quantidade aproximada de material coletada. Conforme dados não publicados, fornecidos pelo DMLU, esse custo, em 2015, foi de aproximadamente $\mathrm{R} \$ 320,00 / \mathrm{t}$.

Segundo estudos do DMLU, presentes no Diagnóstico do Manejo de Resíduos Sólidos Urbanos (2013), a CS tem um total estimado de material coletado de $86 \mathrm{t} /$ dia contra $1.200 \mathrm{t} /$ dia coletados pela coleta tradicional. Entretanto, um estudo (não publicado) empreendido pelo DMLU nas Usinas de Triagem e Compostagens demonstra que o resíduo orgânico que chegou aos aterros sanitários nos anos de 2014 e 2015 é composto de, pelo menos, 23,5 de resíduos recicláveis. Este dado indica também que, nos últimos dez anos, a média de resíduos recicláveis depositados no aterro sanitário era de $30 \%$ do total coletado.

A seguir, um estudo feito nas Usinas de Triagem e Compostagens demonstra a composição do resíduo orgânico que chega aos aterros (Tabela 1). 
Tabela 1 - Caracterização dos Resíduos Mistos de Porto Alegre (\%)

\begin{tabular}{lccccc}
\hline Ano & $\mathbf{1 9 9 4}$ & $\mathbf{1 9 9 7}$ & $\mathbf{2 0 0 2}$ & $\mathbf{2 0 0 9 / 2 0 1 0}$ & $\mathbf{2 0 1 4 / 2 0 1 5}$ \\
\hline Matéria Orgânica & 58,6 & 52,1 & 43,8 & 57,3 & 61,4 \\
Rejeito & 6,0 & 16,0 & 25,5 & 15,9 & 15,2 \\
Vidro & 1,3 & 1,9 & 3,4 & 2,6 & 2,1 \\
Metais & 4,4 & 2,6 & 4,0 & 1,4 & 1,1 \\
Plásticos & 8,4 & 12,4 & 12,4 & 11,2 & 10,4 \\
Papel e Papelão & 21,3 & 15,0 & 10,9 & 11,6 & 9,9 \\
\hline Total Recicláveis & 35,4 & 31,9 & 30,7 & 26,8 & 23,5 \\
\hline
\end{tabular}

Fonte: DMLU, dado não publicado

Esse estudo indica que, em média, nos últimos dez anos, 30\% do resíduo depositado no aterro sanitário eram formados por resíduos potencialmente recicláveis. Ainda sobre o volume arrecadado pela Coleta Seletiva, conforme dados fornecidos pelo DMLU ao SNIS, a quantidade de material arrecadado diminuiu significativamente entre os anos de 2011 e 2013, como exibido na Tabela 2.

Tabela 2 - Quantidade Coletada pela CS e Quantidade Triada pelas UT

\begin{tabular}{llc}
\hline Ano & Total & Triagem \\
\hline 2002 & 7.899 & - \\
2006 & 16.800 & 14.616 \\
2007 & 18.780 & 15.029 \\
2009 & 22.880 & 18.326 \\
2010 & 28.800 & 23.000 \\
2011 & 31.216 & 23.412 \\
2012 & 37.440 & - \\
2013 & 23.400 & 14.400 \\
\hline
\end{tabular}

Fonte: Adaptação Diagnóstico Anual de Resíduos Sólidos SNIS

De acordo com o coordenador Assteplad, essa redução se deve, sobretudo, em decorrência de uma deficiência da coleta seletiva. A mudança de contrato e a falta de fiscalização por parte do departamento contribuíram para essa involução. Em relação ao Novo Código de Limpeza Urbana, Lei 728/14, algumas críticas surgem. O diretor substituto defende que o Código de Limpeza Urbana, instituído pela Lei ${ }^{\circ}$ 234/90, foi uma lei considerada vanguarda no Brasil na época, embora esse Novo Código nada mais seja do que o mesmo código com alguns adendos. Complementando o argumento, no que tange às multas previstas à não separação de resíduos na sua fonte geradora, o diretor substituto elucida que essa obrigação já existia e foi feito apenas um aumento dos valores aplicados. No entanto, o problema que existia antes ainda permanece. Para ele, no caso de resíduos, a dificuldade de fazer valer a lei esbarra na dificuldade de aplicar a sanção de fato e fazer com que tenha algum efeito negativo na vida civil do cidadão. Assinala ainda que a consciência de cidadania não parece ser um conceito homogêneo, o que gera a dificuldade do cumprimento de uma série de regras administrativas e a descrença nos agentes fiscalizadores. Apesar disso, o departamento de fiscalização do DMLU consegue um efeito no âmbito da pessoa jurídica. A fiscalização funciona principalmente através de denúncias, mas rondas também são realizadas a fim de verificar as irregularidades na disposição de resíduos. 
No que tange o aumento de dias de Coleta Seletiva em alguns bairros, o diretor substituto observa não ter havido incremento no volume de material reciclável recolhido que justifique essa decisão. Segundo ele, não existe uma coerência entre essa nova modalidade e a essência socioambiental que o sistema sempre teve. Houve uma baixa na efetividade da coleta, baixando em contrapartida o retorno ambiental desta, com um gasto muito maior de diesel para pouco valor agregado. Além disso, o referido diretor pondera que três dias semanais só faz com que a coleta perca em eficiência. Para o coordenador Assteplad, a Coleta Seletiva deveria estar muito mais desenvolvida e eficiente hoje, depois de 25 anos de sua implantação. Contudo, alerta que tanto a coleta em si como a parte da triagem não só pararam no tempo como involuíram, devido, especialmente, ao desleixo de gestão. Esse descaso é inclusive reconhecido pela nova direção, uma vez que a forma de administração sofreu reestruturação e uma nova empresa foi contratada para fazer a coleta. Apesar dos problemas e do pessimismo quanto à sua capacidade, o sistema de Porto Alegre ainda é considerado referência nacional. No estudo do BNDES de 2013, a Coleta Seletiva de Porto Alegre figura entre as três melhores do país.

\subsection{PERSPECTIVAS PARA A COLETA SELETIVA: AÇÕES E TENDÊNCIAS}

Conforme o diretor da DLC, as ações em andamento em 2015 que estão direta ou indiretamente envolvidas no desenvolvimento e melhoria da Coleta Seletiva são:

- O Serviço de Assistência Socioambiental (SASA) promove encontros e palestras em escolas com o tema de educação ambiental.

- Inaugurado em agosto de 2015, a campanha chamada Estação Recicla POA consiste em um equipamento representando uma unidade de triagem itinerante nos principais eventos da cidade.

- A Troca Solidária que, em convênio com a Ceasa, faz a troca de quatro sacolas de resíduos recicláveis por um quilo de frutas e hortaliças em comunidades carentes.

- O Programa de Entrega de Resíduos Eletrônicos (PERE) no qual uma empresa terceirizada monta pontos de entrega voluntária de materiais eletrônicos em diferentes pontos da cidade.

- A manutenção das Unidades de Destino Certo, em 2015 eram sete pontos.

- Está sendo avaliado junto com a Procempa, o lançamento de um aplicativo do DMLU, a exemplo do 156 - Fala Porto Alegre.

Outro acontecimento importante para o DMLU, segundo o diretor da DLC, foi a instalação dos novos containers de coleta de resíduo orgânico, realizada em janeiro de 2016, contabilizando treze bairros atendidos, com um total de 2.400 containers. No entanto, não existia previsão para a colocação de containers de resíduo reciclável. O mencionado diretor justifica a dificuldade de fiscalizar e impedir a invasão do container por pessoas não autorizadas para retirar o material que seria enviado às Unidades de Triagem. Visão divergente a do diretor-geral 2, de que se há um tipo de container, compulsoriamente teria de ter o outro. A percepção deste do que acontece no centro da cidade é que as pessoas, mesmo separando os seus resíduos, por comodidade ou falta de informação, acabam depositando todo ele dentro do container de resíduo orgânico.

O funcionamento da Coleta Seletiva depende muito de fatores culturais, geográficos, demográficos e do próprio investimento feito no sistema. De acordo com o coordenador Assteplad, o país considerado uma referência mundial em reciclagem é a Alemanha, pois recicla $45 \%$ do resíduo domiciliar. No Brasil, são reciclados apenas 2\%. Em Porto Alegre estima-se que seja 6\%. Ainda segundo este, de acordo com um estudo feito pelo BNDES, Caxias do Sul foi apontada como a melhor Coleta 
Seletiva no Brasil: na categoria de cidades com mais de 100.000 habitantes, $22 \%$ de sua coleta domiciliar é seletiva. Porto Alegre coleta 9\%, com cerca de $30 \%$ de rejeito. Curitiba, que também foi das pioneiras a implantar Coleta Seletiva no Brasil, coleta 7\%.

Caxias do Sul tem uma ótima adesão da população e possui, pelo menos, quatorze Unidades de Triagem. No entanto, quando analisado o material após a triagem, $50 \%$ dele é rejeito, porque as unidades não têm capacidade nem a tecnologia para absorver todo esse material. $\mathrm{O}$ coordenador Assteplad acrescenta que um problema semelhante ocorreu em São Paulo, onde foram implantadas duas grandes unidades de triagem automatizadas em 2014, cada uma recebendo cerca de 250 toneladas de resíduo reciclável por dia. Estas unidades não conseguiam comercializar a matéria-prima, pois não existia uma cadeia consolidada para absorver este material.

Esses são alguns exemplos dos diversos fatores que influenciam no sucesso de um sistema de coleta seletiva, chamada de Cadeia da Reciclagem, por isso, a preocupação em integrar todas as etapas para o sistema fluir de maneira natural. De nada adianta ter a indústria que recicla, se não existe a unidade que faz a triagem do material, assim como não adianta a Unidade de Triagem, se a população não separar seu resíduo. Por fim, não adianta a separação, se não existir todo o resto.

Existem alguns tipos de coleta que são comumente usados: a coleta domiciliar junto ao meio-fio, containers em esquinas e pontos de entregas voluntárias, que abrangem uma área maior. Entre estes existe uma relação inversamente proporcional quanto ao deslocamento do cidadão e o deslocamento do coletor. O coordenador Assteplad acredita que, eventualmente, a tendência é a migração do formato junto ao meio-fio para a coleta em containers nas zonas mais populosas da cidade. Esse formato mantém a cidade mais limpa, diminui a necessidade de viagens para realizar a coleta e facilita para o cidadão na hora de disponibilizar seu resíduo.

Considerando que a Coleta Seletiva é mais cara do que a coleta tradicional, pelos motivos já mencionados, o diretor substituto identifica que o desafio que a gestão enfrenta, em 2016, é o de encontrar meios para acrescer a quantidade de material coletado, sem aumentar o custo. A população tem um papel fundamental, pois conforme exposto, muitos resíduos recicláveis são encaminhados para aterros, ou seja, se fossem separados nas residências, poderiam entrar no ciclo da reciclagem.

Todos os entrevistados concordam sobre a importância da educação ambiental e a constante divulgação mediante campanhas, que deveriam acontecer constante e incansavelmente. Após 25 anos de coleta seletiva, esperava-se que a cultura de separação estivesse introjetada na consciência do povo portoalegrense. Entretanto, não é isto que se observa, o que demonstra a necessidade do contínuo trabalho de conscientização da população. Sobre a adesão da população, o coordenador Assteplad comenta o resultado de uma pesquisa desenvolvida há cerca de dez anos, na qual demonstrava que $2 / 3$ da população de Porto Alegre separavam seus resíduos. Em 2015, ele acredita que esse índice seja menor por não haver uma campanha intensa e frequente de conscientização referente ao sistema de Coleta Seletiva e sua importância.

No entanto, apesar de não ser a totalidade da população a aderir à Coleta Seletiva, o diretor-geral 1 tem motivos para acreditar que os dados não são tão negativos como os divulgados. A partir de dados não oficiais, afirma ter encontrado o resultado de que $60 \%$ da população de Porto Alegre fazem a separação domiciliar. O problema é que esse material não chega, em sua totalidade, às Unidades de Triagem, seja por problemas operacionais, seja de fiscalização da administração pública. Declara que a propaganda negativa informando que apenas uma pequena parte do resíduo produzido é realmente reciclada constitui um desserviço e abala a motivação da população.

Outra frente que melhoraria esse rendimento de recolhimento seria a ação contra as coletas clandestinas, ou seja, veículos não cadastrados junto ao DMLU, que não poderiam fazer essa atividade, 
passam antes da Coleta Seletiva e recolhem os materiais, deixando os rejeitos e o material sem muito valor. Esse problema é reiterado pelo diretor-geral 1 ao expor que, desde a sua gestão, esta situação persiste e se intensifica com o passar do tempo. Para este, faz-se imprescindível uma fiscalização forte o suficiente para inibir essa prática, fato que parece não estar acontecendo. Ainda conforme o diretorgeral 1, quando se encontrava na direção do DMLU, houve um esforço para que os catadores informais fossem atraídos para os galpões, mas admite ser um trabalho de grande complexidade para ser feito. No entanto, defende que o trabalho com os catadores não deve parar, por entender que a limpeza urbana é responsabilidade unicamente da prefeitura e essas pessoas não deveriam estar expostas na rua, e sim trabalhando com dignidade nos galpões ou em outros locais. Segundo o DMLU (2003), o trabalho dos catadores (pessoas que vivem da exploração do lixo em lixões ou associações organizadas) e dos papeleiros (pessoas que percorrem a cidade com carrinhos e, normalmente, trabalham para os donos dos depósitos) compreende uma contribuição importante para a limpeza urbana. A sua organização em associações e cooperativas é essencial para evitar a exploração sofrida por essa mão-de-obra, eliminando assim a necessidade do intermediário, que obtém os maiores ganhos na comercialização do material recolhido nas ruas e triado nos galpões.

Para o diretor-geral 2, o futuro ideal da Coleta Seletiva e da gestão integrada de resíduos, está na diminuição da produção de resíduos, ou seja, na consciência da população em gerar cada vez menos resíduos. Em sua opinião, a ênfase em 2015 estava mais na consequência do que na causa do problema. Entretanto, por razões que envolvem questões sociais e econômicas, a inversão dessa lógica é bastante trabalhosa e demorada, sendo necessário um trabalho de conscientização com a população. Na opinião do diretor-geral 2, aumentar o número de dias de Coleta Seletiva manda uma mensagem errada à população. Outro ponto que o diretor-geral 2 identificou foi a logística reversa, ou seja, a necessidade de responsabilizar as empresas pelo descarte e reciclagem dos materiais que produzem. O DMLU enfrentou diversos problemas com o aparecimento de novos materiais de embalagens, pois não há tecnologia ou viabilidade econômica para reciclá-los. Diante disso, as empresas deveriam assumir a obrigação do descarte correto de seus produtos. Isto as faria planejarem todo o ciclo de vida dos produtos e embalagens e, por extensão, não repassariam o problema da destinação final dos seus produtos para o poder público.

Nesta linha de pensamento, o diretor-geral 1 faz uma reflexão interessante para o futuro ideal para a Coleta Seletiva: "não mais existir a Coleta Seletiva". Nas suas palavras: "Hoje a legislação está completamente diferente. Existe a Política Nacional de Resíduos Sólidos, que obriga a logística reversa através da gestão compartilhada pelo ciclo de vida dos produtos. Essa logística vai se dar através de acordos setoriais". Na visão do diretor-geral 1, caso continue a existir a Coleta Seletiva, que seja como um serviço complementar à logística reversa, prevista na Lei $12.305 / 2010$, que institui a Política Nacional de Resíduos Sólidos através da implementação da responsabilidade compartilhada do ciclo de vida dos produtos. Segundo a qual: "é responsável pela disposição final do resíduo aquele que iniciou seu processo de produção, importou ou fez a distribuição do produto". O consumidor é responsável por fazer a separação, enquanto à iniciativa privada cabe implementar um sistema de logística reversa e o poder público fiscaliza e garante o cumprimento da lei. Até 2015 haviam sido assinados dois acordos setoriais: um com os produtores de óleo lubrificante para carros, que representa uma parcela bem pequena de resíduos; e o segundo, o acordo do setor de lâmpadas fluorescentes. Este último o mais expressivo, visto que abrange a maioria das embalagens disponíveis no mercado, já passou por consulta pública, foi revisado e estava em vias de ser assinado. 
A responsabilidade do resíduo é de quem começa no processo produtivo. Eu, enquanto consumidor, sou obrigado a fazer a separação e quem produz e comercializa tem que implantar a logística reversa. Quem tem que gerenciar o resíduo é a iniciativa privada. O problema do governo é fiscalizar (Diretor-Geral 1).

As associações de catadores também pretendem assinar este acordo, pois desejam trabalhar em conjunto com a iniciativa privada no processo de logística reversa.

\section{CONSIDERAÇÕES FINAIS}

Este trabalho teve como objetivo analisar a trajetória histórica dos 25 anos da Coleta Seletiva na cidade de Porto Alegre. Para tanto, foram entrevistados cinco gestores públicos que tiveram importante participação ao longo deste período, desde a idealização do projeto, passando pela implementação até chegar ao formato existente em 2016.

No decorrer deste trabalho, detalhou-se o período de planejamento, implantação e desenvolvimento do Sistema de Coleta Seletiva, no qual foram colocados em prática alguns projetos paralelos que deram início a uma gestão integrada de resíduos, como a recuperação das áreas degradadas dos lixões e a campanha de educação ambiental com o intuito de conscientizar a população. O modelo de Coleta Seletiva de Porto Alegre, implantado em 1990, foi considerado vanguardista no Brasil, por dar um enfoque à coleta seletiva no seu viés social, recuperando pessoas há muito ignoradas pela sociedade, oferecendo, portanto, oportunidade de maior dignidade e qualidade de vida.

A coleta de dados e entrevistas realizadas permitiram resgatar a história dos 25 anos de Coleta Seletiva em Porto Alegre a partir de diferentes visões. Cabe enfatizar que o Sistema de Coleta Seletiva foi implantado na primeira gestão do Partido dos Trabalhadores na Prefeitura de Porto Alegre, onde permaneceu no poder durante dezesseis anos. Embora nos nove anos seguintes tenha havido alternância de partidos políticos no poder, a Coleta Seletiva se manteve. Alguns gestores entrevistados afirmam que o sistema de CS poderia estar mais desenvolvido e atribuem a culpa à falta de investimentos em divulgação e conscientização da população. Outros defendem mudanças no modelo de coleta e maior investimento na mecanização do processo de separação dos resíduos. Foram identificadas questões técnicas ainda não bem resolvidas, como o custo real da coleta seletiva, uma vez que os caminhões da Coleta Seletiva não são pesados como os da coleta tradicional. Ampliou-se a discussão da coleta seletiva incluindo os catadores e papeleiros, que recolhem resíduos nas ruas. Algumas questões surgem: Qual o volume por eles recolhidos e qual o futuro destes trabalhadores? O futuro da Coleta Seletiva parece estar associado à implementação das leis já aprovadas, que tratam das responsabilidades de cada elo da cadeia na logística reversa, embora estas ainda não estejam bem regulamentadas. Conforme exposto por um dos entrevistados, provavelmente, no futuro a coleta seletiva não seja mais necessária ou seu papel seja apenas complementar a logística reversa.

Como sugestão para trabalhos futuros, destaca-se a necessidade de continuar a análise do serviço de coleta seletiva a fim de verificar se essa estagnação no serviço é algo pontual ou se realmente não há motivação do poder público para fazer maiores investimentos no sistema. Além disso, é interessante abordar a possível implementação da logística reversa e verificar como o cidadão porto-alegrense se comportará e como esta afetará o serviço público prestado há tantos anos.

Nesta pesquisa há a limitação das entrevistas terem sido realizadas somente com os gestores do DMLU. Para complementar essa análise, seria pertinente verificar a percepção dos demais agente envolvidos no sistema de Coleta Seletiva de Porto Alegre, como a população, os catadores e papeleiros, os trabalhadores das Unidades de Triagem e as empresas inseridas no mercado de reciclagem. Uma 
ampliação do escopo permitirá um diagnóstico mais preciso do objeto estudado, levando em consideração todos os âmbitos, nuances e fatores relevantes aos diferentes agentes envolvidos na Coleta Seletiva.

\section{REFERÊNCIAS}

ASSIS, Marcelo Prudente de; MALHEIROS, Tadeu Fabrício; FERNANDES, Valdir; PHILIPPI JR, Arlindo. Avaliação de políticas ambientais: desafios e perspectivas. Saúde e Sociedade, São Paulo, v. 21, supl. 3, p.7-20, 2012.

BRINGHENTI, Jacqueline. Coleta Seletiva de Resíduos Sólidos Urbanos: Aspectos operacionais e da Participação da População. 2004. 234 fl. Tese (Doutorado em Saúde Ambiental) - Faculdade de Saúde Pública da Universidade de São Paulo, São Paulo, 2004.

CABALLERO, Indira Nahomi Viana. Notas sobre o processo de ambientalização do lixo em Porto Alegre/RS. In: 26 ${ }^{\mathrm{a}}$ REUNIÃO BRASILEIRA DE ANTROPOLOGIA, Porto Seguro, 2008. Porto Seguro. Anais... Porto Seguro, 2008.

CALDERONI, Sabetai. Os Bilhões Perdidos no Lixo. 4 ed. São Paulo: Editora Humanitas. 2003.

CAMPOS, Paula Prado de Sousa; PHILIPPI Jr., Arlindo; SANTANA, Paula. Gestão integrada de políticas climáticas e urbanas: uma proposta de avaliação legislativa em municípios da Região Metropolitana de São Paulo. Sustentabilidade em Debate, v. 6 p. 119-137, 2015.

CEMPRE. Guia da Coleta Seletiva de Lixo. CEMPRE. São Paulo, 2014, 2 ed. Disponível em <http://cempre.org.br/upload/arq/o_19q4hmlrq1n8o166v1pl4onjv2ba.pdf>. Acesso em: 25 out. 2015.

DMLU. Descarte Correto: Cartilha do DMLU de julho de 2015. Disponível em <http://www2.portoalegre.rs.gov.br/dmlu/default.php?p_secao=207>. Acesso em: 12 nov. 2015.

FAUGIER, J.; SARGEANT, M. Sampling hard to reach populations. Journal of Advanced Nursing, v. 26, p. 790-797, 1997.

IPEA. Situação Social das Catadoras e dos Catadores de Material Reciclável e Reutilizável. Brasília, 2013. Disponível em:

<http://www.ipea.gov.br/agencia/images/stories/PDFs/situacao_social/131219_relatorio_situacaosocia 1_mat_reciclavel_brasil.pdf > Acesso em: 21 set. 2015.

PREFEITURA DE PORTO ALEGRE. Plano Municupal de Gestão Integrada de Resíduos Sólidos Volume 1 - Diagnóstico e Prognóstico. Porto Alegre, 2013. Disponível em:

<http://lproweb.procempa.com.br/pmpa/prefpoa/dmlu/usu_doc/pmgirs_porto_alegre_volume_1.pdf > Acesso em: 21 set. 2015.

PEREIRA, Sândhya Alves. Coleta Seletiva: Porto Alegre sabe de sobra. In: II SEMINÁRIO AVALIAÇÃO DE EXPERIÊNCIAS BRASILEIRAS DE COLETA SELETIVA, Rio de Janeiro, 1997. Anais... Rio de Janeiro, 1997

ROESCH, Sylvia Maria A.; FERNANDES, Francisco. Como Escrever Casos para o Ensino de Administração. São Paulo: Editora Atlas, 2007.

RIBEIRO, Túlio Franco, LIMA, Samuel do Carmo. Coleta Seletiva de Lixo Domiciliar - Estudo de Caso. Revista Caminhos da Geografia, v. 2, n. 2, p. 50-69, Uberlândia, 2001.

SACHS, Ignacy. Desenvolvimento Sustentável - desafio do século XXI. Ambiente \& Sociedade, v. 7, p. 214-216, 2004. 
SACHS, Ignacy. Caminhos para o desenvolvimento sustentável. Coleção Ideias Sustentáveis. STROH, Paula Yone (Org.). Rio de Janeiro: Garamond, 2000.

SNIS. Diagnóstico do Manejo de Resíduos Sólidos Urbanos de 2002 a 2014. Disponíveis em: < http://www.snis.gov.br/diagnostico-residuos-solidos> Acesso em: 17 nov. 2015.

YIN, Robert K. Estudo de Caso: Planejamento e Métodos. 4 ed. São Paulo: Artmed Editora S.A., 2009. 